\title{
Chemotaxis of Rhizobium leguminosarum biovar phaseoli towards Flavonoid Inducers of the Symbiotic Nodulation Genes
}

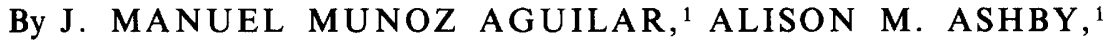 \\ ANDREW J. M. RICHARDS, ${ }^{2}$ GARY J. LOAKE, ${ }^{1}$ \\ MARTIN D. WATSON ${ }^{1}$ AND CHARLES H. SHAW ${ }^{1 *}$ \\ ${ }^{1}$ Department of Botany, University of Durham, Science Laboratories, South Road, \\ Durham DH1 3LE, UK \\ ${ }^{2}$ ICI Biological Products Business, PO Box 1, Billingham, Cleveland, TS23 ILB, UK
}

(Received 28 March 1988; revised 2 June 1988)

\begin{abstract}
Chemotaxis of Rhizobium leguminosarum biovar phaseoli RP8002 towards a range of carbohydrates, phenolic compounds and flavonoids was assayed. Xylose (peak response $10^{-4} \mathrm{M}$ ), sucrose (peak response $10^{-6} \mathrm{M}$ ) and raffinose (peak response $10^{-5} \mathrm{M}$ ) were strong chemoattractants amongst the carbohydrates, whilst glucose, fructose, galactose and maltose produced little or no detectable response. Of the monocyclic phenolic compounds, vanillyl alcohol, $p$-hydroxybenzoic acid (both peak responses $10^{-6} \mathrm{M}$ ) and 3,4-dihydroxybenzoic acid (peak response $10^{-4} \mathrm{M}$ ) all evoked strong chemotactic responses. Amongst the nod-inducing flavonoids, apigenin and luteolin were both strong chemoattractants (peaks at $10^{-5} \mathrm{M}$ ) while naringenin produced a very low response. Competition experiments suggest that apigenin and luteolin are recognized by a common receptor, but that there exists a separate receptor for luteolin alone. The inhibitors of nod-induction, umbelliferone and acetosyringone, both produced strong chemotactic responses, with peaks at $10^{-3} \mathrm{M}$ and $10^{-2} \mathrm{M}$ respectively. This evidence is indicative of a role for chemotaxis towards nod-inducing flavonoids in the initiation of root nodule formation by rhizobia, and also suggests that chemotaxis may influence the host range of the interaction.
\end{abstract}

\section{INTRODUCTION}

The formation of nitrogen-fixing nodules by Rhizobium upon legume roots is a complex and highly organized process. The nodulation (nod) functions are usually clustered on large (sym) plasmids in the microbial symbiont (Rossen et al., 1987). Flavonoids in legume root exudates interact with the nodD product to effect induction of the other nod genes (Peters et al., 1986; Redmond et al., 1986; Firmin et al., 1986; Zaat et al., 1987; Horvath et al., 1987; Djordjevic et al., 1987; Kosslak et al., 1987). The exact functions of the induced nod genes are unclear, although $\operatorname{nod} A, B$ and $C$ are required for root hair curling and mutations in the other nod loci affect subsequent nodule formation (Rossen et al., 1987).

A similar relationship exists between Agrobacterium tumefaciens and susceptible plants. Wound exuded phenolic compounds, e.g. acetosyringone, induce the virulence (vir) operons on the Ti-plasmid, via an interaction with the products of vir $A$ and $G$ (Okker et al., 1984; Stachel $e t$ al., 1985, 1986; Stachel \& Zambryski, 1986; Winans et al., 1986; Rogowsky et al., 1987). The induced vir functions mediate T-DNA transfer to the plant cell; expression of the integrated T-DNA leads to proliferation of cells to form a crown gall tumour (Nester et al., 1984; Lichtenstein, 1986). Ti-plasmid harbouring strains of $A$. tumefaciens are chemotactic towards vir-inducing phenolic compounds, such as acetosyringone (Ashby et al., 1987, 1988). This

Abbreviations: PHBA, p-hydroxybenzoic acid; DHBA, 3,4-dihydroxybenzoic acid. 
response requires vir $A$ and $G$ (Shaw et al., 1988) and has a threshold of $<10^{-8} \mathrm{M}$ (Ashby et al., 1987). This suggests that chemotaxis to vir-inducing wound exudates is responsible for attracting and guiding virulent $A$. tumefaciens towards susceptible cells (Shaw et al., 1986).

Agrobacterium and Rhizobium exhibit similar motility patterns (Götz \& Schmitt, 1987; Loake et al., 1988). Rhizobia are chemotactic to a variety of amino acids and sugars (Götz et al., 1982; Gaworzewska \& Carlile, 1982). Moreover, attraction to a legume glycoprotein (Currier \& Strobel, 1976, 1977), root exudates (Currier \& Strobel, 1976; Gitte et al., 1978; Gaworzewska \& Carlile, 1982) and localized sites upon legume roots (Gulash et al., 1984) has been reported for Rhizobium. Furthermore, motile strains of $R$. meliloti appear to have an advantage in nodule formation over non-motile mutants (Ames \& Bergman, 1981).

In view of the similarities between Agrobacterium and Rhizobium, we undertook an investigation of chemotaxis in Rhizobium leguminosarum biovar phaseoli.

\section{METHODS}

Organism and growth. All experiments were done with $R$. leguminosarum biovar phaseoli RP8002, because in comparative experiments it was significantly more motile than three other biovars of $R$. leguminosarum (JIINT83K3, RL1040 and RL16015). Bacteria were grown either in Rhizobium Initiation Medium (RIM; $0.5 \%$ tryptone, $0 \cdot 3 \%$ yeast extract, $0 \cdot 13 \% \mathrm{CaCl}_{2}$ ) or Minimal A supplemented with glucose (MinA + G; Miller, 1972). Periodically, a fresh isolate of motile bacteria was prepared from the stock culture by three passages through swarm plates (RIM solidified with $0.25 \%$ agar), selecting organisms from the perimeter of the swarm at each passage. Chemotactic responses of successive isolates were reproducible. Chemotaxis medium (CM; Adler, 1973) was autoclaved and attractants were filter sterilized prior to use.

Chemotaxis assay. Capillary assays (Adler, 1973) were done in duplicate, using washed stationary phase cells at a culture density of approximately $10^{9}$ cells $\mathrm{ml}^{-1}$, as previously described (Ashby et al., 1987). Bacteria from the exponential phase gave qualitatively similar, but quantitatively lower responses. Values presented represent the mean of duplicate assays done on at least two separate occasions. All values recorded fell within $20 \%$ of the mean.

Microscopy. Motility was observed at room temperature, using a Nikon Optiphot microscope with phasecontrast optics, and a Hitachi HV-720K CCTV camera. Behaviour and speed measurements were made during slow motion playback of recorded motility, using a Ferguson 3 V 23 video recorder and a Hitachi VM-920K video monitor.

Attractants. All sugars were obtained from Sigma, flavonoids from Apin Chemicals (Oxford, UK) and phenolic compounds from Aldrich. Phenolic compounds were solubilized by neutralization with $\mathrm{KOH}$, and flavonoids in a $1: 1(\mathrm{v} / \mathrm{v})$ mixture of acetonitrile and dimethylsulphoxide, neither of which are chemoattractants for $R$. leguminosarum biovar phaseoli.

\section{RESULTS}

\section{Chemotaxis towards sugars}

A variety of mono-, di- and trisaccharides were tested as chemoattractants for $R$. leguminosarum biovar phaseoli using the capillary assay (Adler, 1973; Ashby et al., 1987). Of the monosaccharides tested (Fig. 1) only xylose evoked a chemotactic response, yielding a relatively broad peak with an apparent optimum of $10^{-4} \mathrm{M}$. No significant chemotaxis was recorded towards fructose, galactose or glucose. Sucrose (peak chemotaxis at $10^{-6} \mathrm{M}$ ) and the trisaccharide raffinose (peak at $10^{-5} \mathrm{M}$ ), evoked a significant response (Fig. 2) while a barely detectable response was produced by maltose.

\section{Chemotaxis towards phenolic compounds}

In view of our recent demonstration of the significance of chemotaxis of A. tumefaciens towards phenolic plant exudates (Ashby et al., 1987, 1988; Shaw et al., 1988) it was important to ascertain whether $R$. leguminosarum biovar phaseoli exhibited similar responses. All four compounds tested evoked some form of chemotactic response (Fig. 3). Vanillyl alcohol and $p$ hydroxybenzoic acid (PHBA) both gave sharp peaks at $10^{-6} \mathrm{M}, 3,4$-dihydroxybenzoic acid (DHBA) resulted in a broad peak with an apparent maximum at $10^{-4} \mathrm{M}$, and acetosyringone evoked a response which increased towards $10^{-2} \mathrm{M}$. Solubility problems above that concentration prevented a proper peak from being observed. These results are at considerable variance to those recorded for $\boldsymbol{A}$. tumefaciens (see Discussion). It is of interest to note that acetosyringone is an inhibitor of nod-induction in R. leguminosarum (Firmin et al., 1986). 


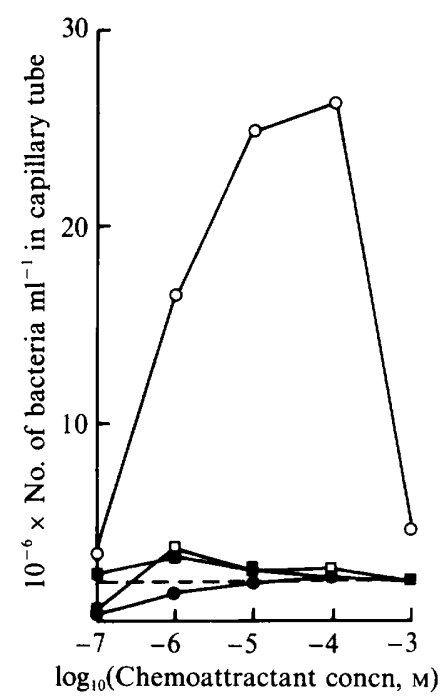

Fig. 1

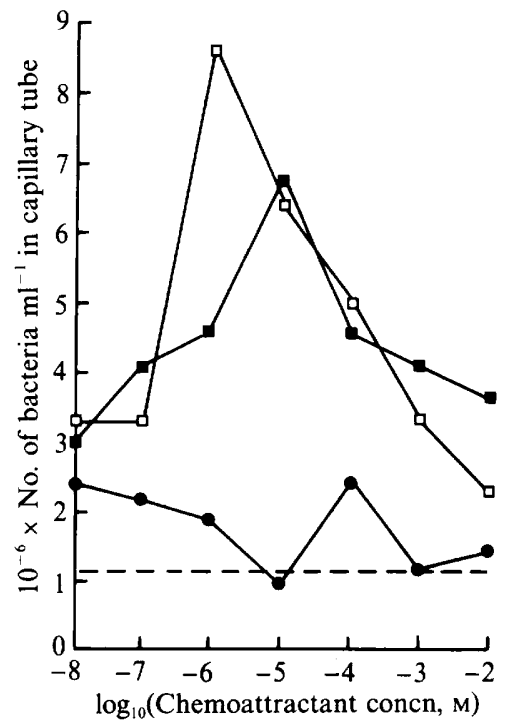

Fig. 2

Fig. 1. Dose response curves of motility of $R$. leguminosarum biovar phaseoli towards the monosaccharides xylose $(O)$, fructose $(\bigcirc)$, galactose $(\square)$ and glucose $(\square)$. ---, Number of bacteria attracted into a capillary containing chemotaxis medium alone.

Fig. 2. Dose response curves of motility of $R$. leguminosarum biovar phaseoli towards the oligosaccharides sucrose $(\square)$, maltose $(\bigcirc)$ and raffinose $(\square) .--$, As Fig. 1.

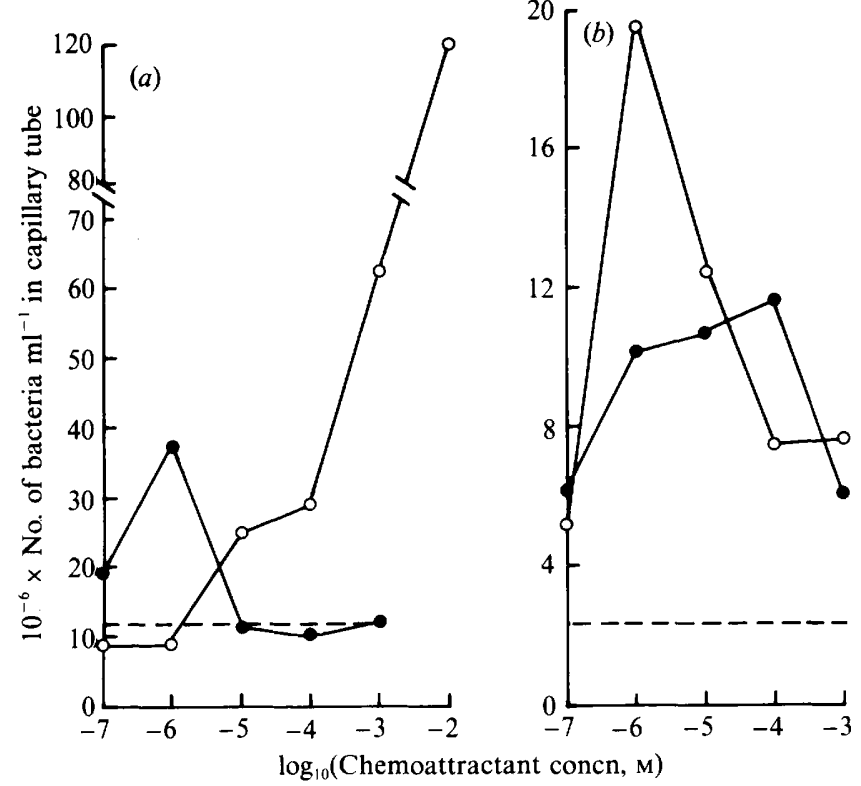

Fig. 3

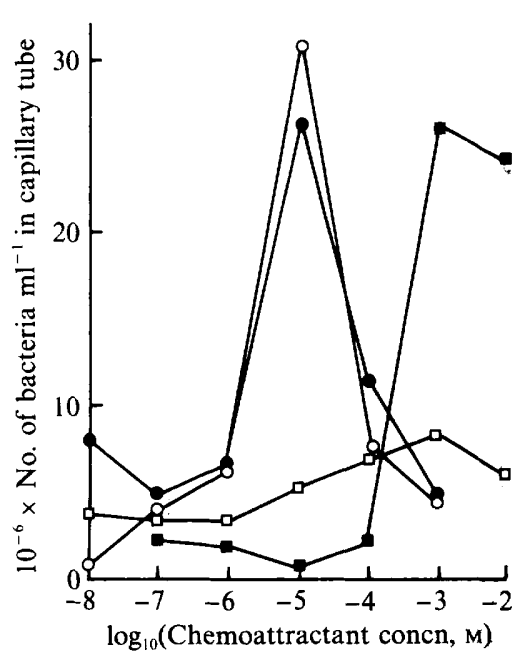

Fig. 4

Fig. 3. Dose response curves of motility of $R$. leguminosarum biovar phaseoli towards the phenolic compounds $(a)$ acetosyringone $(O)$ and vanillyl alcohol $(O)$, and $(b)$ PHBA $(O)$ and DHBA (O). ---, As Fig. 1.

Fig. 4. Dose response curves of motility of $R$. leguminosarum biovar phaseoli towards the flavonoids apigenin $(O)$, luteolin $(O)$, naringenin $(\square)$ and umbelliferone $(\square)$. Control values of bacteria attracted into a capillary containing chemotaxis medium alone were $4.5 \times 10^{6} \mathrm{ml}^{-1}$. 
Table 1. Competitive chemotaxis assays for $R$. leguminosarum, biovar phaseoli

$\quad \begin{aligned} & \text { Attractant in } \\ & \text { capillary }\left(10^{-5} \mathrm{M}\right)\end{aligned}$
Chemotaxis medium
Apigenin
Luteolin
Apigenin + luteolin
Apigenin + luteolin
Apigenin + luteolin

Attractant in
pool $\left(10^{-4} \mathbf{M}\right)$
-
-
-
-
Apigenin
Luteolin

$10^{-6} \times$ No. of cells $\mathrm{ml}^{-1}$
in capillary
$8 \cdot 7$
$28 \cdot 3$
$29 \cdot 4$
$38 \cdot 6$
$22 \cdot 1$
$6 \cdot 9$

\section{Chemotaxis towards flavonoids}

Due to their significance as nod-inducers, it was important to test chemotaxis towards flavonoids. Both apigenin and luteolin, which are nod-inducers for $R$. meliloti, R. leguminosarum and $R$. trifolii (Peters et al., 1986; Firmin et al., 1986; Zaat et al., 1987; Djordjevic et al., 1987) are potent chemoattractants, producing sharp peaks at $10^{-5} \mathrm{M}$ (Fig. 4). In contrast, naringenin, a nod-inducer for $R$. leguminosarum and $R$. trifolii (Zaat et al., 1987; Djordjevic et al., 1987) evoked a very weak response. Intriguingly, umbelliferone, which has been reported to be an inhibitor of nod-induction in $R$. trifolii (Djordjevic et al., 1987), acted as a strong chemoattractant for $R$. leguminosarum biovar phaseoli, exhibiting a peak at $10^{-3} \mathrm{M}$.

As apigenin and luteolin are structurally similar, competition experiments were done to ascertain whether they share a receptor (Table 1). At $10^{-5} \mathrm{M}$ both flavonoids evoked a strong chemotactic response, which was marginally improved when the two compounds were used together as attractant. This response was slightly attenuated by the inclusion, in the bacterial pool, of $10^{-4} \mathrm{M}$-apigenin. However, when $10^{-4} \mathrm{M}$-luteolin was included in the bacterial pool, chemotaxis towards the apigenin/luteolin mixture dropped below the level of detection. These results indicate that saturation with luteolin blocks chemotaxis towards apigenin, but apigenin at saturation only partially impedes chemotaxis towards luteolin. This suggests that there exist in $R$. leguminosarum biovar phaseoli two separate receptor/binding sites for luteolin, one of which also recognizes apigenin.

\section{DISCUSSION}

This paper is the first survey of chemotaxis in Rhizobium leguminosarum biovar phaseoli, and illustrates the significant differences between Rhizobia. The response of $R$. leguminosarum biovar phaseoli towards carbohydrates is almost completely different to the recorded behaviour of other biovars of $R$. leguminosarum, meliloti and lupini (Götz et al., 1982; Gaworzewska \& Carlile, 1982). Xylose is also an attractant for $R$. leguminosarum, and glucose fails to attract $R$. meliloti, but all other responses of $R$. leguminosarum biovar phaseoli are distinct. What is also distinct about the $R$. leguminosarum biovar phaseoli responses is their greater sensitivity than in other Rhizobia (Götz et al., 1982; Gaworzewska \& Carlile, 1982). Sucrose, for example, produces a peak response at $10^{-6} \mathrm{M}$, reminiscent of the behaviour of $A$. tumefaciens (Loake et al., 1988 ). It is quite intriguing that $R$. leguminosarum biovar phaseoli is not chemotactic towards some sugars (glucose, fructose and maltose) which are major constituents of legume root exudates (Gaworzewska \& Carlile, 1982) but is attracted towards other important components of these exudates (xylose, sucrose and raffinose).

Chemotaxis towards flavonoids and phenolic compounds is particularly interesting. The responses towards phenolic compounds are significantly different to those of $A$. tumefaciens (Ashby et al., 1987, 1988). PHBA and DHBA are both chemoattractants for $A$. tumefaciens (Ashby et al., 1988), non-inducers of the nod genes, and degradation products of flavones (Djordjevic et al., 1987). A. tumefaciens is also chemotactic to non-vir-inducing phenolic compounds such as vanillyl alcohol (Ashby et al., 1987). Non-inducing attractants, such as sugars and some phenolic compounds, may thus serve to guide Agrobacterium and Rhizobium to the vicinity of plant roots. 
Both apigenin and luteolin are strong chemoattractants for $R$. leguminosarum biovar phaseoli, and nod-inducers for R. meliloti, R. leguminosarum biovar viciae and $R$. trifolii (Peters et al., 1986; Firmin et al., 1986; Zaat et al., 1987; Djordjevic et al., 1987). The chemotactic response is highly sensitive, and within the same concentration range as that evoking maximal nod-induction in $R$. trifolii (Djordjevic et al., 1987). Intriguingly, naringenin, closely related and also a nod-inducer for $R$. leguminosarum biovar viciae and $R$. trifolii (Zaat et al., 1987; Djordjevic et al., 1987) failed to elicit a significant chemotactic response. These responses may play a role in the determination of rhizobial host range. It has recently been demonstrated that apigenin and naringenin, but not luteolin, are good nod-inducers in $R$. leguminosarum biovar phaseoli (Carmen Quinto, personal communication). Thus, our results indicate that chemotaxis and nod-induction do not necessarily correlate. A similar conundrum is observed in $R$. meliloti, where some nodinducers, such as luteolin, do act as chemoattractants, but others, such as apigenin and naringenin, do not, and indeed the latter suppresses chemotaxis towards luteolin (CaetanoAnolles et al., 1988). As legume root exudates are complex in composition (Gitte et al., 1978; Gaworzewska \& Carlile, 1982; Redmond et al., 1986; Firmin et al., 1986; Djordjevic et al., 1987) the different spectra of compounds triggering chemotaxis and nod-induction may be part of an interaction which is significant in host range determination in Rhizobium.

The exaggerated response to high concentrations of acetosyringone and umbelliferone, both of which have been reported to be inhibitors of nod-induction (Firmin et al., 1986; Djordjevic et al., 1987) is intriguing. Djordjevic et al. (1987) proposed that the secretion of umbelliferone at or near the root tip in clover would prevent nodule initiation in this vicinity. However, it seems unlikely that the concentrations of these inhibitors required to evoke peak chemotactic responses in $R$. leguminosarum biovar phaseoli $\left(10^{-2}\right.$ to $\left.10^{-3} \mathrm{M}\right)$ would ever be encountered in the rhizosphere. Secretion of different attractants from distinct root zones could explain the attraction of $R$. meliloti to localized sites on legume roots (Gulash et al., 1984).

This paper presents evidence suggestive of an involvement of chemotaxis towards flavonoids in the initiation of legume root nodules by rhizobia. Moreover, as different flavonoids evoke widely differing responses, there is a possibility that the specificity of chemotaxis is involved in the determination of rhizobial host range. In $A$.tumefaciens a similar relationship exists, and the same genetic loci are involved in acetosyringone mediated chemotaxis and vir-induction. It will therefore be of interest to elucidate the genetic basis of chemotaxis in $R$. leguminosarum biovar phaseoli.

The authors would like to express their gratitude to the members of the Durham Agrobacterium Group for continual advice and stimulating discussions. A.M.A. and G.J.L. were supported by SERC studentships.

\section{REFERENCES}

ADLER, J. (1973). A method for measuring chemotaxis and use of the method to determine optimum conditions for chemotaxis by Escherichia coli. Journal of General Microbiology 74, 77-91.

AMES, P. \& Bergman, K. (1980). Competitive advantage provided by bacterial motility in the formation of nodules by Rhizobium meliloti. Journal of Bacteriology 148, 728-729.

AshbY, A. M., Watson, M. D. \& Shaw, C. H. (1987). A Ti-plasmid determined function is responsible for chemotaxis towards the plant wound product acetosyringone. FEMS Microbiology Letters 41, 189192.

Ashby, A. M., Watson, M. D., Loake G. J. \& Shaw, C. H. (1988). Ti-plasmid specified chemotaxis of Agrobacterium tumefaciens $\mathrm{C} 58 \mathrm{C}^{1}$ towards vir-inducing phenolics and soluble factors from monocotyledonous and dicotyledonous plants. Journal of Bacteriology (in the Press).
Caetano-Anolles, G., Crist-Estes, D. K. \& Bauer, W. D. (1988). Chemotaxis of Rhizobium meliloti to the plant flavone luteolin requires functional nodulation genes. Journal of Bacteriology (in the Press).

Currier, W. W. \& Strobel, G. A. (1976). Chemotaxis of Rhizobium spp. to plant root exudates. Plant Physiology 57, 820-823.

Currier, W. W. \& Strobel, G. A. (1977). Chemotaxis of Rhizobium spp. to a glycoprotein produced by birdsfoot trefoil roots. Science 196, 434-436.

Djordjevic, M. A., Redmond, J. A., Batley, M. \& RolfE, B. G. (1987). Clovers secrete specific phenolic compounds which either stimulate or repress nod gene expression in Rhizobium trifolii. EMBO Journal 6, 1173-1179.

Firmin, J. L., Wilson, K. E., Rossen, L. \& Johnston, A. W. B. (1986). Flavonoid activation of nodulation genes in Rhizobium reversed by other compounds present in plants. Nature, London 324, 90-92. 
Gaworzewska, E. T. \& Carlile, M. J. (1982). Positive chemotaxis of Rhizobium leguminosarum and other bacteria towards root exudates from legumes and other plants. Journal of General Microbiology 128, 1179-1188.

GitTe, R. R., Rai, P. V. \& Patil, R. B. (1978). Chemotaxis of Rhizobium spp. towards root exudate of Cicer arietinum L. Plant and Soil 50, 553-566.

Gulash, M., Ames, P., Larosiliere, R. C. \& BergMAN, K. (1984). Rhizobia are attracted to localised sites on legume roots. Applied and Environmental Microbiology 48, 149-152.

GöTz, R. \& SCHMITT, R. (1977). Rhizobium meliloti swims by unidirectional, intermittent rotation of right-handed flagellar helices. Journal of Bacteriology $169,3146-3150$

GöTZ, R., LimMER, N., OBER, K. \& SCHMITT, R. (1982). Motility and chemotaxis in two strains of Rhizobium with complex flagella. Journal of General Microbiology 128, 789-798.

HoRvath, B., Bachem, C. W. B., Schell, J. \& KoNDOROSI, A. (1987). Host-specific regulation of nodulating genes in Rhizobium is mediated by a plant signal, interacting with the nodD gene product. EMBO Journal 6, 841-848.

Kosslak, R. M., Bookland, R., Barkei, J., PaAren, H. E. \& APPELbaUM, E. R. (1987). Induction of Bradyrhizobium japonicum common nod genes by isoflavones isolated from Glycine max. Proceedings of the National Academy of Sciences of the United States of America 84, 7428-7432.

LICHTENSTEIN, C. (1986). A bizarre vegetal bestiality. Nature, London 322, 682-683.

Loake, G. J., Ashby, A. M. \& Shaw, C. H. (1988). Attraction of Agrobacterium tumefaciens C $58 \mathrm{C}^{1}$ towards sugars involves a highly sensitive chemotaxis system. Journal of General Microbiology 134, 1427-1432.

MilleR, J. H. (1972). Experiments in Molecular Genetics. Cold Spring Harbor, NY: Cold Spring Harbor Laboratory.

Nester, E. W., Gordon, M. P., Amasino, R. M. \& YANOFSKY, M. (1984). Crown gall: a molecular and physiological analysis. Annual Review of Plant Physiology 35, 387-413.

OKKer, R. J. H., SPaink, H., Hille, J., van Brussel, T. A. N., LugTeNBERG, B. \& SCHILPEROORT, R. A. (1984). Plant inducible promoter of the Agrobacterium tumefaciens Ti-plasmid. Nature, London 312, 564-566.
Peters, N. K., Frost, J. W. \& Long, S. R. (1986). A plant flavone, luteolin, induces expression of Rhizobium meliloti nodulation genes. Science 233, 977-980.

Redmond, J. W., BATley, M., DJoRdjevic, M. A., INNES, R. W., Kuempel, P. L. \& Rolfe, B. G. (1986). Flavones induce expression of nodulation genes in Rhizobium. Nature, London 323, 632-635.

Rogowsky, P. M., Close, T. J., ChImera, J. A., SHAW, J. J. \& KaDO, C. I. (1987). Regulation of the vir genes of Agrobacterium tumefaciens plasmid pTiC58. Journal of Bacteriology 169, 5101-5112.

Rossen, L., DAvis, E. O. \& JohNSTON, A. W. B. (1987). Plant-induced expression of Rhizobium genes involved in host specificity and early stages of nodulation. Trends in Biochemical Sciences 12, 430433.

Shaw, C. H., Ashby, A. M. \& Watson, M. D. (1986). Plant tumour induction. Nature, London 324, 415.

Shaw, C. H., Ashby, A. M., Brown, A., Royal, C., LOAKE, G. J. \& SHAw, C. H. (1988). vir $A$ and $G$ are the Ti-plasmid functions required for chemotaxis of Agrobacterium tumefaciens towards acetosyringone. Molecular Microbiology 2, 413-418.

StACHEL, S. E. \& ZAMBRYSKI, P. (1986). virA and virG control the plant-induced activation of the T-DNA transfer process of $A$. tumefaciens. Cell 46, 325-333.

Stachel, S. E., Messens, E., Van Montagu, M. \& ZAMBRYSKI, P. (1985). Identification of the signal molecules produced by wounded plant cells that activate T-DNA transfer in Agrobacterium tumefaciens. Nature, London 318, 624-629.

Stachel, S. E., Nester, E. W. \& Zambryski, P. C. (1986). A plant cell factor induces Agrobacterium tumefaciens vir gene expression. Proceedings of the National Academy of Sciences of the United States of America 83, 379-383.

Winans, S. C., Ebert, P. R., Stachel, S. E., Gordon, M. P. \& Nester, E. W. (1986). A gene essential for Agrobacterium virulence is homologous to a family of positive regulatory loci. Proceedings of the National Academy of Sciences of the United States of America 83, 8278-8282.

ZaAt, S. A. J., Wijffelman, C. A., SPaink, H. P., VaN BRUSSEL, A. A. N., OKKER, R. J. H. \& LUGTENBERG, B. J. J. (1987). Induction of the nodA promoter of Rhizobium leguminosarum sym plasmid pRL1JI by plant flavanones and flavones. Journal of Bacteriology 169, 198-204. 